\title{
Radioiodine Treatment and Thyroid Hormone Suppression Therapy for Differentiated Thyroid Carcinoma: Adverse Effects Support the Trend toward Less Aggressive Treatment for Low-Risk Patients
}

\author{
E.N. Klein Hesselink T.P. Links \\ Department of Endocrinology, University Medical Center Groningen, University of Groningen, Groningen, The Netherlands
}

\section{Key Words}

Differentiated thyroid carcinoma · Radioiodine treatment .

Thyroid hormone suppression therapy · Adverse effects .

Low-risk patients

\begin{abstract}
Over the past decades, the incidence of differentiated thyroid carcinoma (DTC) has steadily increased, with especially a growing number of low-risk patients. Whereas DTC used to be treated rather aggressively, it is now acknowledged that aggressive treatment does not affect outcome for low-risk patients and that it can induce adverse effects. In this review an overview of the most clinically relevant adverse effects of radioiodine treatment and thyroid hormone suppression therapy (THST) is presented, and the trend toward less aggressive treatment for low-risk patients is outlined. Salivary gland dysfunction occurs in roughly $30 \%$ of patients, and is probably due to the concentration of radioiodine in the salivary glands by the sodium/iodide symporter. Beta radiation from radioiodine can result in sialoadenitis and eventually fibrosis and loss of salivary function. Furthermore, patients can experience bone marrow dysfunction following radioiodine treatment. Although this is in general subclinical and transient, patients that receive very high cumulative radioiodine doses may be at risk for more severe bone marrow dys-
\end{abstract}

function. THST can induce adverse cardiovascular effects in patients with DTC, such as diastolic and systolic dysfunction, and also adverse vascular and prothrombotic effects have been described. Finally, the effects of THST on bone formation and resorption are outlined; especially postmenopausal women with DTC on THST seem to be at risk of bone loss. In the past years, advances have been made in preventing lowrisk patients from being overtreated. Improved biomarkers are still needed to further optimize risk stratification and personalize medicine.

(C) 2015 European Thyroid Association Published by S. Karger AG, Basel

The incidence and prevalence of differentiated thyroid carcinoma (DTC) are steadily increasing. For example, the number of female DTC survivors in the USA was estimated to be 470,020 in 2014 , and is expected to be 645,330 in 2024 [1]. In particular the number of low-risk patients is increasing [2], for whom it is not clear whether treatment benefits outweigh the burden of therapy, and adverse effects could be prevented when overaggressive treatment is omitted.

Over the past decades, standardized treatment has consisted of a total thyroidectomy accompanied by a central or lateral neck lymph node dissection if indicated,

\footnotetext{
KARGER 125\%

C) 2015 European Thyroid Association

Published by S. Karger AG, Basel

E-Mail karger@karger.com

$2235-0640 / 15 / 0042-0082 \$ 39.50 / 0$
}

Prof. Dr. T.P. Links

University of Groningen, University Medical Center Groningen

Department of Endocrinology, HPC AA31, PO Box 30.001

NL-9700 RB Groningen (The Netherlands)

E-Mail t.p.links@umcg.nl 
followed by radioiodine $\left({ }^{131} \mathrm{I}\right)$ ablation, and thyroid hormone suppression therapy (THST) during follow-up. Although treatment is tolerated well by most patients, adverse effects of DTC treatment have been increasingly recognized [3], and were - and still are - reason for a debate on the required aggressiveness of DTC treatment [4] Moreover, there is increasing doubt whether low-risk DTC patients benefit from radioiodine ablation and THST at all. The aim of the current review is to give an overview of the most clinically relevant adverse effects of radioiodine treatment and THST, and to discuss trends toward less aggressive treatment for patients with DTC.

\section{Radioiodine Therapy}

Radioiodine therapy has been a mainstay for DTC treatment for decades. Due to the fairly specific uptake in thyroid cells, therapy is effective and relatively safe. In recent years, the adverse effects of radioiodine treatment have been increasingly acknowledged, and treatment indications critically reassessed. Focusing on the salivary glands and the bone marrow, we will discuss the main adverse effects of radioiodine therapy, and consider current views on radioiodine treatment for low-risk patients in particular.

\section{Effects on Salivary Glands}

Salivary glands have been estimated to concentrate iodine at 7 to 700 times the plasma level (fig. 1a, b) [5]. This is probably linked to the presence of the sodium-iodide symporter (NIS) located in both thyroid follicular and salivary gland epithelial cells $[6,7]$. Saliva that is produced in the acini drains into intercalated ducts, after which striated ducts transport saliva to the excretory ducts. In human salivary glands, NIS is mainly expressed in the striated ducts, while acini do not contain NIS (fig. 1c) [6]. By emitting beta radiation, radioiodine can cause an acute and/or chronic inflammatory reaction in the salivary gland parenchyma (sialoadenitis). As the ductal compartment is particularly exposed to radiation, luminal debris and narrowing of the duct lumen may occur $[8,9]$. In addition to early toxicity, radioiodine can induce late effects (fig. 2). Damage to salivary gland stem cells, which have been proposed to mainly reside in the ductal compartment and replenish progenitor, and eventually to ductal and acinar cells (fig. 1d) [10], can become apparent after one or several cell divisions, which take 60-120 days [11]. Radiation injury can ultimately lead to fibrosis of salivary gland excretory tissue with loss of acini in particular, which can result in further decline of salivary gland function.

Radioiodine-induced sialoadenitis can cause pain and swelling, reduced salivary flow (hyposalivation), the sensation of oral dryness (xerostomia), and an increased risk of developing oral infections and dental caries [12]. In a prospective study, 20 of 76 DTC patients (26\%) developed complaints of pain, swelling or xerostomia either within $48 \mathrm{~h}$ or at least 3 months after radioiodine treatment [13]. The majority of patients still had complaints 1 year after ablation. An earlier report showed that 33\% of DTC patients developed sialoadenitis within 3 months after ablation therapy, and $43 \%$ had complaints of decreased salivary gland function 1 year after the last radioiodine treatment [14]. However, the reported frequency of salivary gland complaints varies widely [5], which may be due to the nonuniform method of xerostomia assessment. Moreover, studies assessing hyposalivation by measuring parotid and submandibular saliva flow rates are, to the best of our knowledge, lacking for DTC patients.

In general, parotid glands are affected more often than submandibular glands, and bilateral parotitis is more common than unilateral parotitis [14-16]. This may be due to a higher saliva clearance rate in submandibular glands, which has been proposed to explain the higher NIS expression, but lower cumulative radioiodine activity found in submandibular versus parotid glands [6].

In addition to patients with clinical overt sialoadenitis and xerostomia, many more patients have subclinical salivary gland dysfunction after radioiodine treatment. This was illustrated by a study of 79 patients in which both subjective (xerostomia complaints) and objective (technetium-99m scintigraphy) signs of salivary gland dysfunction were studied [15]. Salivary gland scintigraphy provides an objective assessment of salivary gland uptake and excretion function. However, it remains unclear which method is the gold standard for detection of radioiodine-induced salivary gland dysfunction. In the mentioned study, 33\% had subjective and 51\% had objective signs of salivary gland dysfunction during in the first year after radioiodine therapy. Moreover, 28 patients developed scintigraphic salivary gland dysfunction not earlier than in the third follow-up year, whereas only 2 had newonset xerostomia.

\section{Prevention and Treatment}

The main recommendations to prevent salivary gland damage during radioiodine treatment include generous intake of fluids, use of gustatory sialogogues (lemon juice/ 
Fig. 1. Uptake of radioiodine in the parotid (a) and submandibular glands (b) on the SPECT-CT scan, performed 7 days after radioiodine therapy. c The NIS is mainly expressed in the striated ducts of salivary glands (S), and to a lesser extent in the intercalated (rectangle) and excretory ducts (E). Acini (A) do not express NIS. Reprinted with permission [6], (C) 2013 Mary Ann Liebert Inc. d Schematic representation of a salivary gland, with proposed locations of stem cells in excretory and striated ducts, and progenitor cells within the striated and intercalated ducts. The stem cell pool supplies the progenitor cell pool, which in turn replenishes the population of duct and acinar cells. Both stem and progenitor cells have the capacity to self-renew and differentiate. Reprinted with permission [10], (C) 2013 Wiley.

Fig. 2. Proposed mechanisms of radioiodine-induced salivary gland toxicity.
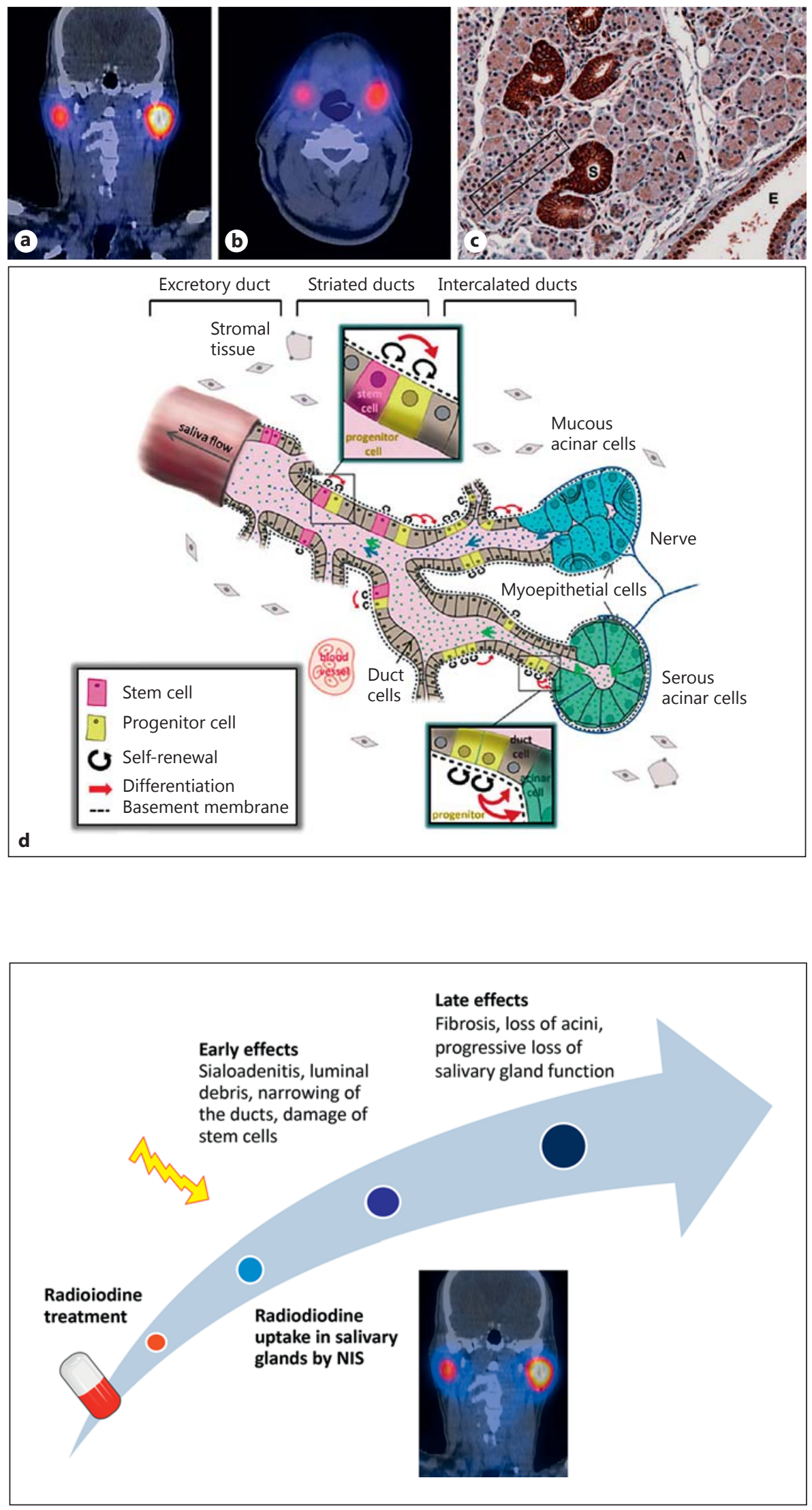
candy, vitamin C), and gland massage [5]. However, whether or not to use sialogogues immediately after radioiodine treatment remains controversial, as there are conflicting results in the literature regarding this topic [1720]. It was proposed that salivary gland blood flow and consequent radioiodine exposure was increased in patients who start using sialogogues within an hour after radioiodine ingestion $[17,18]$. Others, however, found a decreased rather than increased radioiodine absorbed dose in the parotid glands after early initiation of sialogogues $[19,20]$. The cholinergic pilocarpine was not found to decrease salivary gland damage following radioiodine treatment in DTC patients [21]. The effect may have been obscured by high-dose dexamethasone, administered to all patients as an antiemetic. No beneficial effects were found for amifostine, a radical scavenger, either [22].

Proposed treatment of radioiodine-induced sialoadenitis is mostly symptomatic with generous fluid intake and administration of gustatory or masticatory sialogogues. Furthermore, anti-inflammatory drugs or referral to a dentist or oral surgeon may be useful [5]. A new development within the field is the application of sialoendoscopy, which allows for the dilatation of duct stenoses, lavage of the ductal system and removal of mucus plugs. A subjective improvement in 23 of 30 patients after one treatment could be achieved using this technique [16]. Furthermore, preparation for radioiodine treatment with recombinant human thyroid-stimulating hormone (rhTSH) instead of thyroid hormone withdrawal (THW) has been proposed to induce less salivary gland toxicity, as THW-induced hypothyroidism causes a transient impairment of renal function, and therefore a slower renal clearance of radioiodine. In a prospective study of 148 patients on rhTSH [23], 5.4 and $4.7 \%$ of patients had oral complaints 12 and 18 months postablation, respectively. This is lower than reported in the mentioned prospective studies with THW preparation for radioiodine therapy $[13,15]$. Studies cannot directly be compared though, as different questionnaires and definitions were used for salivary gland damage. Finally, a selective NIS blocker for salivary glands has been proposed [6], but as yet this is still a distant prospect.

\section{Effects on Bone Marrow}

The bone marrow can be affected by radioiodine treatment. This is probably due to radiation damage from protein-bound or free-circulating radioiodine [24], or a local effect in case of uptake of radioiodine in bone metastases.

In most studies, a decrease in thrombocytes and leucocytes (as a manifestation of bone marrow dysfunction) was found in a subset of patients [24-27]. In a study performed half a century ago in 159 thyroid carcinoma patients, 35\% experienced anemia, 10\% leucopenia and 3\% had subnormal platelet counts after radioiodine treatment [25]. These cytopenias were subclinical in most cases, and blood counts recovered within a year after the last radioiodine treatment. Data on the long-term effects of radioiodine of this study are unfortunately not reliable. Other studies had comparable results with regard to subclinical toxicity and recovery of blood counts $[26,27]$, and additionally suggested higher toxicity with increasing cumulative doses.

Although the mentioned studies draw a reassuring picture with regard to bone marrow toxicity of radioiodine treatment, they were hampered by low patient numbers and a rather short follow-up. High-risk DTC patients with distant (bone) metastases may be at risk of bone marrow toxicity. These patients often receive high cumulative radioiodine doses that may result in high bone marrow radiation levels, and vital bone marrow may be replaced by tumor tissue, leading to impaired hematopoiesis. This is illustrated by a study of 107 DTC patients with initial bone metastases, treated with highdose radioiodine therapies [28]. Four patients died from aplasia and 4 from acute myeloid leukemia after mean radioiodine doses of 70 and $87 \mathrm{GBq}(1,892$ and 2,351 $\mathrm{mCi})$, respectively.

\section{Prevention and Treatment}

It has been suggested to use blood and bone marrow dosimetry studies to determine the radioiodine dose that can be safely administered [29], but this approach could not prevent blood count decreases in 50 thyroid carcinoma patients who received a median dose of $606 \mathrm{mCi}$ [30]. Alternatively, preparation for radioiodine treatment with rhTSH instead of THW has been proposed to induce less bone marrow toxicity. rhTSH preparation is associated with a lower red marrow absorbed dose [31], and in a study performed in 15 elderly DTC patients no clinically relevant bone marrow toxicity was observed after radioiodine therapy [32]. However, no differences in peripheral blood counts were found between patients prepared with THW and rhTSH in a larger-scale study [33]. Stem cell preservation and, if indicated, a later bone marrow transplantation, has been proposed for those patients who are expected to receive high cumulative doses of radioiodine [34]. Despite a case report on stem cell preservation [35], there are no data available about whether and when to perform such a procedure and what outcome to expect. 
Radioiodine Treatment in Low-Risk DTC

Until the end of the 20th century, most DTC patients received high-dose radioiodine ablation therapy [36]. Since then, the indication and appropriate dose for radioiodine therapy have been much debated. A multi-institutional registry study and systematic literature analysis showed that radioiodine treatment was not associated with improved survival for low-risk patients [4, 37]. Moreover, randomized controlled multicenter studies showed that low-dose radioiodine therapy of $1.1 \mathrm{GBq}(30 \mathrm{mCi})$ was not inferior to a high dose of $3.7 \mathrm{GBq}(100 \mathrm{mCi})$ with regard to short-term ablation success in DTC patients with a low [38] and low-to-intermediate risk [39]. In another prospective randomized study of 309 low-risk DTC patients, the 5-year efficacy of ablation with 30,60 and $100 \mathrm{mCi}$ was compared [40]. No difference in outcome at 5 years postablation was found between the groups. However, $22 \%$ of patients ablated with $30 \mathrm{mCi}$ needed another radioiodine therapy, whereas for patients initially treated with 60 or $100 \mathrm{mCi}$, these numbers were 13 and $11 \%$, respectively. The long-term efficacy of a low- versus high-dose radioiodine ablation therefore remains unclear, but a trend toward lower radioiodine activities or even omission of ablation in low-risk patients is clearly evident. A multicenter randomized trial that is currently recruiting low-risk DTC patients (NCT01398085) aims to study whether refraining from ablation is noninferior to low-dose ablation therapy with regard to the 5-year disease-free survival rate. This trial will finally give an answer to the question of whether or not radioiodine ablation is really needed in low-risk patients and, moreover, whether, in addition to short-term outcome, long-term outcome is noninferior.

\section{Thyroid Hormone Suppression Therapy}

As with radioiodine treatment, a trend toward less aggressive THST has occurred in the past 2 decades. Lifelong THST used to be recommended for all DTC patients [36], but in the current guidelines tapering of THST after the initial treatment or several years is recommended [41, 42], especially for low-risk patients. As THST induces an iatrogenic (subclinical) hyperthyroid state, adverse effects on the cardiovascular system and bone density were expected on pathophysiological grounds, and could be confirmed in clinical studies.

\section{Cardiovascular Effects}

Triiodothyronine is an important cardiovascular regulator. In myocytes it regulates transcription of multiple genes coding for proteins that influence cardiac function, and it affects several ion channels [43]. By controlling intracellular calcium and potassium concentrations, high triiodothyronine levels enhance cardiac contractility. Furthermore, triiodothyronine lowers systemic vascular resistance by acting on the vascular smooth muscle cells. Via the renin-angiotensin-aldosterone system, blood volume and therefore cardiac output increases, resulting in a hyperdynamic circulation [44]. This can lead to cardiac hypertrophy, and could eventually cause systolic and diastolic dysfunction. THST may induce elevated intracellular triiodothyronine levels and consequently adverse cardiovascular effects, but this remains uncertain as it has been shown that circulating thyroid hormones do not necessarily reflect intracellular concentrations [45].

The adverse cardiac effects of long-term THST were recognized about 2 decades ago. Diastolic dysfunction and an increased left ventricular mass and wall thickness were found in a heterogeneous group of DTC and multinodular goiter patients on TSH-suppressive doses of levothyroxine [46]. The impaired diastolic function has been confirmed in DTC patients on THST for at least 10 years [47]. Importantly, in this study diastolic dysfunction reversed after a follow-up of 6 months in patients randomized to restore euthyroidism, while it remained in those randomized to stay on THST.

Furthermore, THST can induce subtle ventricular dysfunction in DTC patients in the short-term, whereas more pronounced ventricular dysfunction may occur with longterm therapy. Subtle ventricular dysfunction has been shown using 2D speckle tracking echocardiography [48], a relatively new technique that measures ventricular deformation in the longitudinal, radial and circumferential plains (fig. 3). Especially longitudinal myocardial strain has been shown to be of great value in detecting subclinical myocardial changes in cancer survivors, which can precede clinically relevant left ventricular ejection fraction (LVEF) decreases and heart failure [49]. An impaired systolic function in terms of decreased longitudinal and circumferential strain was found in DTC patients on short-term THST as compared to controls [48]. Radial strain, which is less sensitive to hemodynamic stress or ischemia, was preserved along with the LVEF. However, for DTC patients on longterm THST of the aforementioned study [47], a significantly lower LVEF (although within the reference range) was found as compared to controls.

Besides cardiac adverse effects, adverse vascular and prothrombotic effects of THST have also been described, albeit often in single studies. The arterial elasticity of both small and large arteries was decreased in DTC patients on
Klein Hesselink/Links 


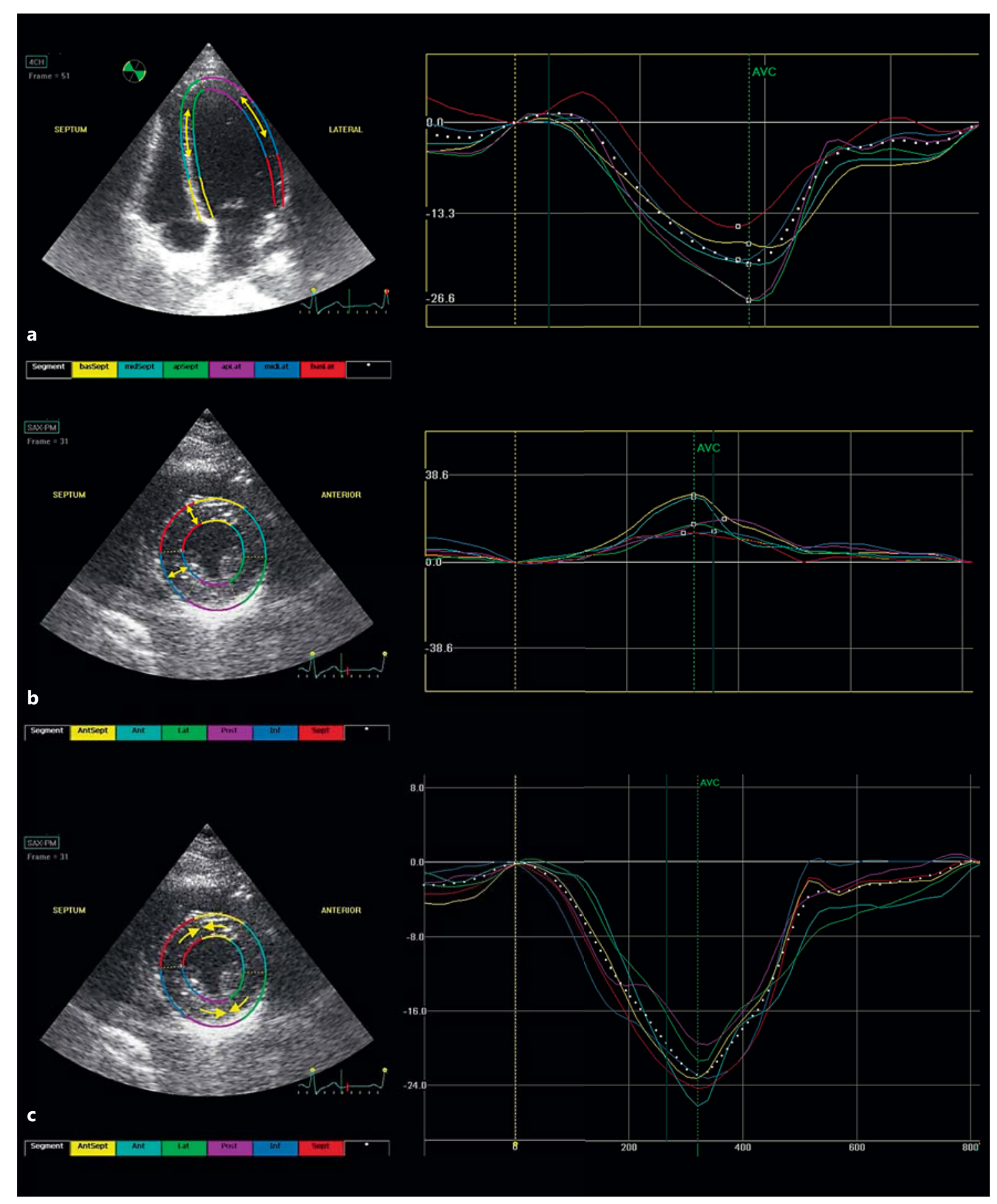

Fig. 3. 2D speckle tracking strain echocardiography measurements of longitudinal (a), radial (b) and circumferential strain (c). Left ventricular long- (a) and short-axis views (b, c) are shown on the left, with corresponding time-strain curves on the right. Arrows indicate the type of strain (deformation) measured. Strain measurements are performed in six myocardial segments (indicated with different colors) in each plane. The average strain of the six segments resembles global strain for the particular recording. AVC = Aortic valve closure. 


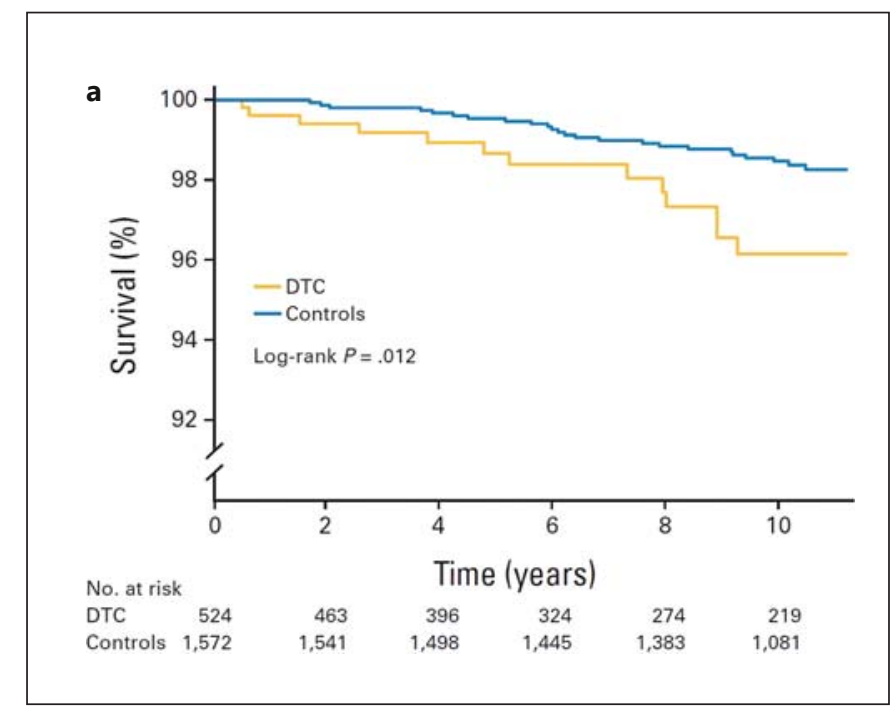

Fig. 4. Kaplan-Meier curves of cardiovascular mortality in DTC patients versus controls (a), and cardiovascular mortality by TSH category (b), for patients with DTC. TSH category 1 represents a geometric mean TSH during follow-up below $0.02 \mathrm{mU} / \mathrm{l}$; category

long-term THST, as compared to controls [50]. Furthermore, a prothrombotic state was found in 14 DTC patients on THST that resulted in a hyperthyroid state, as compared to the same population after THW-induced hypothyroidism [51]. Although the mechanisms of the mentioned cardiovascular derangements are incompletely understood, they could add to the cardiovascular risk of DTC patients.

DTC patients also have an increased risk of clinically overt cardiovascular disease. In a cross-sectional study of 136 thyroid carcinoma patients on THST, prevalent atrial fibrillation $(\mathrm{AF})$ was found in $10.3 \%$ whereas the predicted prevalence would be $1-2 \%$ for the age- and sex-adjusted general population [52]. There was no difference in TSH between patients that did and those that did not have $\mathrm{AF}$, although the reliability of the latter finding was limited as only one TSH level was used. In a recent largerscale retrospective study of low- and intermediate-risk DTC patients, no relation between the median TSH level during follow-up and AF was found either [53]. In our center, a 3.3-fold increased risk of cardiovascular mortality was found in a cohort of 524 DTC patients, as compared to 1,572 age- and sex-matched controls, independent of cardiovascular risk factors [54]. Moreover, an association between lower TSH levels during follow-up and a higher risk of cardiovascular mortality was found within the DTC cohort, which remained after adjustment for cardiovascular risk factors and DTC characteristics (fig. 4).

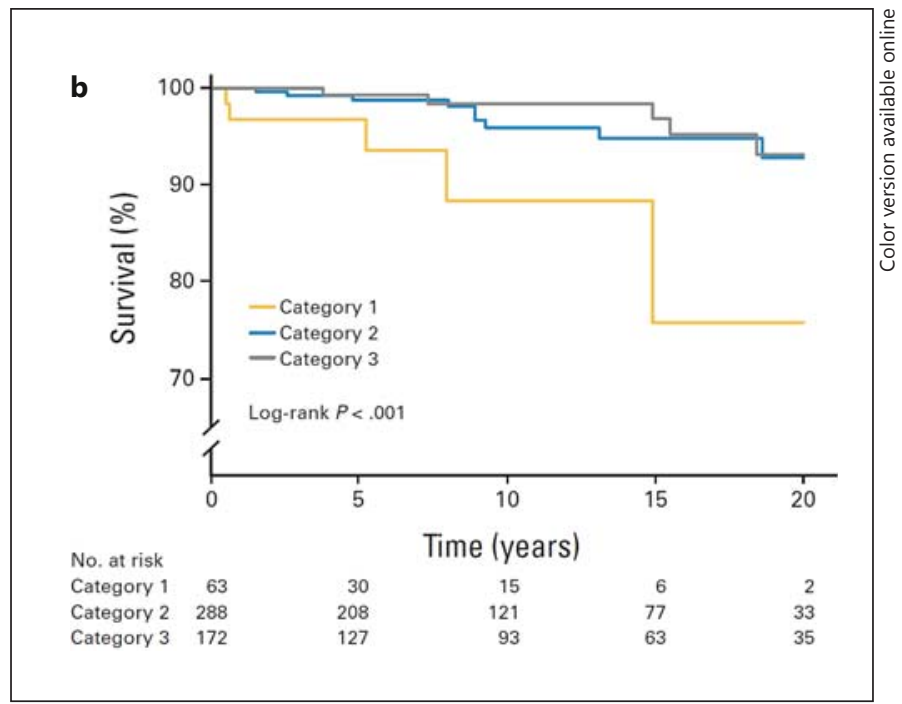

2 represents a geometric mean TSH of $0.02-0.2 \mathrm{mU} / \mathrm{l}$, and category 3 represents a geometric mean TSH over $0.2 \mathrm{mU} / \mathrm{l}$. Reprinted with permission [54], (C) 2013 American Society of Clinical Oncology. All rights reserved.

Prevention and Treatment

Although data on the prevention and treatment of THST-related cardiovascular adverse effects in DTC patients are lacking, a close follow-up with identification and treatment of cardiovascular risk factors and attention for rhythm disturbances seems justified.

\section{Effects on Bone Density}

Both triiodothyronine and TSH have been reported to affect bone formation and resorption, although triiodothyronine seems to be the major bone regulator, with a smaller fine-tuning role for TSH [55]. Nuclear triiodothyronine receptors (TRs) are widely expressed in bone. T3 mainly acts on the TRal in bone, as unraveled from experiments with TR $\alpha$ and TR $\beta$ mutant mice [56]. During skeletal development, high T3 levels in loss-of-function TR $\beta$ mutant mice (with a defective pituitary feedback) induced rapid bone formation and mineralization with premature closure of growth plates, whereas during adulthood elevated $\mathrm{T} 3$ resulted in accelerated bone remodeling with net bone loss [56-58]. These TR $\beta$ mutant mice had skeletal hyperthyroidism, whereas in other experiments (loss-of-function) TRa mutant mice showed a phenotype of skeletal hypothyroidism, confirming the important role of TRa in bone metabolism. In addition to T3, TSH has been proposed to affect bone formation and resorption directly via TSH receptors on osteoblasts and osteoclasts 
[59]. TSH receptor knockout mice showed increased bone loss, even after administration of thyroid tissue extract that induced euthyroidism. As the latter was initiated at weaning, findings could also be due to severe hypothyroidism during the first weeks after birth, which is a critical phase for bone development [55]. DTC patients on THST often have high-normal triiodothyronine levels [60] and a low TSH; both can provide a rationale for adverse effects of THST on bone mineral density (BMD).

Postmenopausal women with DTC may suffer from bone loss [53, 61-63], while THST does not - or to a much lesser extent - affect BMD in premenopausal women and men $[64,65]$. Of female DTC patients randomized to THST (but not those randomized to a TSH in the normal range), patients of 50 years and older had a significantly decreased BMD within 1 year, which was not applicable to those under 50 years of age [61]. Furthermore, a 3.5-fold increased risk for developing osteoporosis was found for female DTC patients with a suppressed TSH as compared to patients with a nonsuppressed TSH, taking into account osteoporosis risk at baseline [53]. After additional adjustment for age, a 4.3-fold increased risk was found, indicating that THST is more harmful with increasing age. More subtle bone loss may be assessed by peripheral quantitative computed tomography [63].

In contrast, no adverse effects of THST in DTC patients were found at all in several cross-sectional studies that included postmenopausal women [66-68]. In a cohort of 49 DTC patients and controls, no differences were found in BMD of the femur and lumbar spine [67]. In another study, BMD Z-scores of DTC patients on longterm THST were in the reference range [68]. Discrepancies in outcome could be due to differences in the degree and duration of THST, or inclusion or exclusion of patients with factors that can increase (postsurgical hypoparathyroidism [69], use of vitamin D, calcium or bisphosphonates) or decrease BMD (history of overt hyperthyroidism, estrogen or vitamin D deficiency).

\section{Prevention and Treatment}

Oral calcium and bisphosphonates can prevent BMD losses in postmenopausal women with DTC, but seem redundant in premenopausal women and men. A few studies showed promising data on this issue, but replication in larger studies is lacking, and prevention of BMD loss in postmenopausal DTC patients is not common practice. In one study, postmenopausal women with DTC randomized to receive oral calcium showed a stable BMD during a 2-year follow-up, whereas significant decreases were found in those randomized to placebo [70]. In an- other trial with mainly premenopausal women and men, patients were randomized to receive the parenteral bisphosphonate pamidronate and levothyroxine, or levothyroxine and a placebo [71]. DTC patients that received pamidronate showed significant increases in BMD during the 2-year follow-up, whereas the placebo arm had a stable BMD over time.

\section{THST in Low-Risk Patients}

Data on adverse effects of THST are accumulating, while there is an increasing uncertainty about the indication of THST for DTC patients, especially for those with a low risk of recurrence. Based on historical data and expert opinion [36, 72, 73], lifelong THST has been advocated for all DTC patients for decades. However, in a later study it was shown that THST, as well as other treatment modalities, did not affect survival outcomes for stage I patients [4]. THST with TSHs in the subnormal and undetectable range did improve survival for stage II and stage III/IV DTC patients, respectively. Following the results of a unique Japanese study, it is advocated to use less aggressive treatment for papillary thyroid carcinoma patients as well [74]. Such results are hard to compare with those obtained in the West though, since diagnostic and treatment approaches widely differ. Furthermore, in a recent study performed in low- and intermediate-risk DTC patients, TSH levels during follow-up did not affect the recurrence rate [53]. An optimal TSH level of 0.9-1 $\mathrm{mU} / \mathrm{l}$ was proposed for patients with a low or intermediate risk, as with this level no increased risk for osteoporosis was found, and a low risk of recurrence was maintained. With the latter studies in combination with an increased acknowledgement of the adverse effects of THST, a shift toward less aggressive THST has been made. For low-risk patients after initial treatment, a TSH in the low-normal range is advocated, while for high-risk patients a suppressed TSH during follow-up remains recommended for at least several years [41, 42].

\section{Conclusion}

In this review, an overview of the most clinically relevant adverse effects of THST and radioiodine treatment in DTC patients has been presented, and the shift toward less aggressive treatment for low-risk patients was outlined. For the growing category of low-risk patients with indolent tumors, aggressive treatment does not affect outcome, but it can induce adverse effects. In recent years, advances have been made to prevent low-risk patients 
from overtreatment. Better biomarkers are still needed to further personalize medicine and ensure adequate treatment for those with a high risk, and spare low-risk patients from needless adverse effects.

\section{Acknowledgements}

The authors are grateful for the important contributions of A. Vissink (Department of Oral and Maxillofacial Surgery, UMCG, Groningen, The Netherlands) to the salivary glands section, and for the contributions of A.H. Brouwers (Department of Nuclear Medicine and Molecular Imaging, UMCG, Groningen, The Netherlands) and Y.M. Hummel (Department of Cardiology, UMCG, Groningen, The Netherlands) to figures $1 \mathrm{a}, \mathrm{b}$ and 3, respectively.

\section{Disclosure Statement}

Both authors can assure that this paper represents honest work, and that no actual or potential financial interests were capable of influencing judgment.

\section{References}

$\checkmark 1$ DeSantis CE, Lin CC, Mariotto AB, Siegel RL, Stein KD, Kramer JL, Alteri R, Robbins AS, Jemal A: Cancer treatment and survivorship statistics, 2014. CA Cancer J Clin 2014;64: 252-271.

-2 Ahn HS, Kim HJ, Welch HG: Korea's thyroidcancer 'epidemic'- screening and overdiagnosis. N Engl J Med 2014;371:1765-1767.

-3 Hyer SL, Newbold K, Harmer CL: Early and late toxicity of radioiodine therapy: detection and management. Endocr Pract 2010;16: 1064-1070.

-4 Jonklaas J, Sarlis NJ, Litofsky D, Ain KB, Bigos ST, Brierley JD, Cooper DS, Haugen BR, Ladenson PW, Magner J, Robbins J, Ross DS, Skarulis M, Maxon HR, Sherman SI: Outcomes of patients with differentiated thyroid carcinoma following initial therapy. Thyroid 2006;16:1229-1242.

5 van Nostrand D: Sialoadenitis secondary to ${ }^{131}$ I therapy for well-differentiated thyroid cancer. Oral Dis 2011;17:154-161.

-6 La Perle KM, Kim DC, Hall NC, Bobbey A, Shen DH, Nagy RS, Wakely PE Jr, Lehman A, Jarjoura D, Jhiang SM: Modulation of sodium/iodide symporter expression in the salivary gland. Thyroid 2013;23:1029-1036.

7 Spitzweg C, Joba W, Schriever K, Goellner JR, Morris JC, Heufelder AE: Analysis of human sodium iodide symporter immunoreactivity in human exocrine glands. J Clin Endocrinol Metab 1999;84:4178-4184.

8 Mandel SJ, Mandel L: Radioactive iodine and the salivary glands. Thyroid 2003;13:265-271.

$\checkmark 9$ Mandel L: Hyposalivation: the roles of radioactive iodine and stapes surgery. J Oral Maxillofac Surg 2013;71:e76-e80.

10 Pringle S, van Os R, Coppes RP: Concise review: adult salivary gland stem cells and a potential therapy for xerostomia. Stem Cells 2013;31:613-619.

11 Vissink A, Mitchell JB, Baum BJ, Limesand $\mathrm{KH}$, Jensen SB, Fox PC, Elting LS, Langendijk JA, Coppes RP, Reyland ME: Clinical management of salivary gland hypofunction and xerostomia in head-and-neck cancer patients: successes and barriers. Int I Radiat Oncol Biol Phys 2010;78:983-991.
12 Walter MA, Turtschi CP, Schindler C, Minnig P, Muller-Brand J, Muller B: The dental safety profile of high-dose radioiodine therapy for thyroid cancer: long-term results of a longitudinal cohort study. J Nucl Med 2007;48:16201625.

13 Hyer S, Kong A, Pratt B, Harmer C: Salivary gland toxicity after radioiodine therapy for thyroid cancer. Clin Oncol (R Coll Radiol) 2007;19:83-86.

-14 Alexander C, Bader JB, Schaefer A, Finke C, Kirsch CM: Intermediate and long-term side effects of high-dose radioiodine therapy for thyroid carcinoma. J Nucl Med 1998;39: 1551-1554.

15 Solans R, Bosch JA, Galofre P, Porta F, Rosello J, Selva-O'Callagan A, Vilardell M: Salivary and lacrimal gland dysfunction (sicca syndrome) after radioiodine therapy. J Nucl Med 2001;42:738-743.

16 de Luca R, Vicidomini A, Trodella M, Tartaro G, Colella G: Sialoendoscopy: A viable treatment for $\mathrm{I}^{131}$ induced sialoadenitis. Br J Oral Maxillofac Surg 2014;52:641-646.

17 Nakada K, Ishibashi T, Takei T, Hirata K, Shinohara K, Katoh S, Zhao S, Tamaki N, Noguchi Y, Noguchi S: Does lemon candy decrease salivary gland damage after radioiodine therapy for thyroid cancer? J Nucl Med 2005;46: 261-266.

18 Jentzen W, Balschuweit D, Schmitz J, Freudenberg L, Eising E, Hilbel T, Bockisch A, Stahl A: The influence of saliva flow stimulation on the absorbed radiation dose to the salivary glands during radioiodine therapy of thyroid cancer using ${ }^{124} \mathrm{I}$ PET(/CT) imaging. Eur J Nucl Med Mol Imaging 2010;37:2298-2306.

19 van Nostrand D, Atkins F, Bandaru VV, Chennupati SP, Moreau S, Burman K, Wartofsky L: Salivary gland protection with sialagogues: a case study. Thyroid 2009;19: 1005-1008.

20 Kulkarni K, van Nostrand D, Atkins F, Mete M, Wexler J, Wartofsky L: Does lemon juice increase radioiodine reaccumulation within the parotid glands more than if lemon juice is not administered? Nucl Med Commun 2014 $35: 210-216$
21 Silberstein EB: Reducing the incidence of ${ }^{131} \mathrm{I}$ induced sialadenitis: the role of pilocarpine. J Nucl Med 2008:49:546-549.

22 Kim SJ, Choi HY, Kim IJ, Kim YK, Jun S, Nam HY, Kim JS: Limited cytoprotective effects of amifostine in high-dose radioactive iodine 131-treated well-differentiated thyroid cancer patients: analysis of quantitative salivary scan. Thyroid 2008;18:325-331.

23 Rosario PW, Calsolari MR: Salivary and lacrimal gland dysfunction after remnant ablation with radioactive iodine in patients with differentiated thyroid carcinoma prepared with recombinant human thyrotropin. Thyroid 2013;23:617-619.

24 Tofani A, Sciuto R, Cioffi RP, Pasqualoni R, Rea S, Festa A, Gandolfo GM, Arista MC, Maini CL: Radioiodine-induced changes in lymphocyte subsets in patients with differentiated thyroid carcinoma. Eur J Nucl Med 1999;26:824-829.

25 Haynie TP, Beierwaltes WH: Hematologic changes observed following I-131 therapy for thyroid carcinoma. J Nucl Med 1963;4:85-91.

26 Keldsen N, Mortensen BT, Hansen HS: Haematological effects from radioiodine treatment of thyroid carcinoma. Acta Oncol 1990; 29:1035-1039.

-27 Menzel C, Grunwald F, Schomburg A, Palmedo $H$, Bender H, Spath G, Biersack HJ: 'High-dose' radioiodine therapy in advanced differentiated thyroid carcinoma. J Nucl Med 1996;37:1496-1503.

28 Petrich T, Widjaja A, Musholt TJ, Hofmann M, Brunkhorst T, Ehrenheim C, Oetting G, Knapp WH: Outcome after radioiodine therapy in 107 patients with differentiated thyroid carcinoma and initial bone metastases: sideeffects and influence of age. Eur J Nucl Med 2001;28:203-208.

-29 Tuttle RM, Leboeuf R, Robbins RJ, Qualey R, Pentlow K, Larson SM, Chan CY: Empiric radioactive iodine dosing regimens frequently exceed maximum tolerated activity levels in elderly patients with thyroid cancer. J Nucl Med 2006;47:1587-1591. 
-30 Padovani RP, Tuttle RM, Grewal R, Larson SM, Boucai L: Complete blood counts are frequently abnormal 1 year after dosimetryguided radioactive iodine therapy for metastatic thyroid cancer. Endocr Pract 2014;20: 213-220.

- 31 Taieb D, Sebag F, Farman-Ara B, Portal T, Baumstarck-Barrau K, Fortanier C, Bourrelly M, Mancini J, De Micco C, Auquier P, ConteDevolx B, Henry JF, Mundler O: Iodine biokinetics and radioiodine exposure after recombinant human thyrotropin-assisted remnant ablation in comparison with thyroid hormone withdrawal. J Clin Endocrinol Metab 2010;95:3283-3290.

-32 Amdur RJ, Dan T, Mazzaferri E: Absence of bone marrow toxicity in elderly patients treated with recombinant human thyroid-stimulating hormone and empirically dosed radioiodine for thyroid cancer. Am J Clin Oncol 2013;36:348-353.

-33 Molinaro E, Leboeuf R, Shue B, Martorella AJ, Fleisher M, Larson S, Tuttle RM: Mild decreases in white blood cell and platelet counts are present one year after radioactive iodine remnant ablation. Thyroid 2009;19:10351041.

-34 Dorn R, Kopp J, Vogt H, Heidenreich P, Carroll RG, Gulec SA: Dosimetry-guided radioactive iodine treatment in patients with metastatic differentiated thyroid cancer: largest safe dose using a risk-adapted approach. J Nucl Med 2003;44:451-456.

-35 Freesmeyer M: A severe haematologic adverse reaction after high dosage radioiodine therapy following blood stem cell mobilization with growth factors. Nuklearmedizin 2011;50:N34-N36.

36 Mazzaferri EL: Papillary and follicular thyroid cancer: selective therapy. Compr Ther 1981;7:6-14.

37 Sacks W, Fung CH, Chang JT, Waxman A, Braunstein GD: The effectiveness of radioactive iodine for treatment of low-risk thyroid cancer: a systematic analysis of the peer-reviewed literature from 1966 to April 2008. Thyroid 2010;20:1235-1245.

- 38 Schlumberger M, Catargi B, Borget I, Deandreis D, Zerdoud S, Bridji B, Bardet S, Leenhardt L, Bastie D, Schvartz C, Vera P, Morel O, Benisvy D, Bournaud C, Bonichon F, Dejax C, Toubert ME, Leboulleux S, Ricard M, Benhamou E, et al: Strategies of radioiodine ablation in patients with low-risk thyroid cancer. N Engl J Med 2012;366:1663-1673.

-39 Mallick U, Harmer C, Yap B, Wadsley J, Clarke S, Moss L, Nicol A, Clark PM, Farnell K, McCready R, Smellie J, Franklyn JA, John R, Nutting CM, Newbold K, Lemon C, Gerrard G, Abdel-Hamid A, Hardman J, Macias $\mathrm{E}$, et al: Ablation with low-dose radioiodine and thyrotropin alfa in thyroid cancer. N Engl J Med 2012;366:1674-1685.
-40 Kukulska A, Krajewska J, Gawkowska-Suwinska M, Puch Z, Paliczka-Cieslik E, Roskosz J, Handkiewicz-Junak D, Jarzab M, Gubala E, Jarzab B: Radioiodine thyroid remnant ablation in patients with differentiated thyroid carcinoma (DTC): prospective comparison of long-term outcomes of treatment with 30, 60 and $100 \mathrm{mCi}$. Thyroid Res 2010;3:9.

41 Cooper DS, Doherty GM, Haugen BR, Kloos RT, Lee SL, Mandel SJ, Mazzaferri EL, McIver B, Pacini F, Schlumberger M, Sherman SI, Steward DL, Tuttle RM: Revised American Thyroid Association management guidelines for patients with thyroid nodules and differentiated thyroid cancer: The American Thyroid Association (ATA) Guidelines Taskforce on Thyroid Nodules and Differentiated Thyroid Cancer. Thyroid 2009;19:1167-1214.

42 Pacini F, Schlumberger M, Dralle H, Elisei R, Smit JW, Wiersinga W, European Thyroid Cancer Taskforce: European consensus for the management of patients with differentiated thyroid carcinoma of the follicular epithelium. Eur J Endocrinol 2006;154:787-803.

43 Klein I, Ojamaa K: Thyroid hormone and the cardiovascular system. N Engl J Med 2001; 344:501-509.

44 Klein I, Danzi S: Thyroid disease and the heart. Circulation 2007;116:1725-1735.

45 Escobar-Morreale HF, Obregon MJ, Escobar del Rey F, Morreale de Escobar G: Replacement therapy for hypothyroidism with thyroxine alone does not ensure euthyroidism in all tissues, as studied in thyroidectomized rats. J Clin Invest 1995;96:2828-2838.

46 Biondi B, Fazio S, Carella C, Amato G, Cittadini A, Lupoli G, Sacca L, Bellastella A, Lombardi G: Cardiac effects of long term thyrotropin-suppressive therapy with levothyroxine. J Clin Endocrinol Metab 1993;77:334-338.

47 Smit JW, Eustatia-Rutten CF, Corssmit EP, Pereira AM, Frolich M, Bleeker GB, Holman ER, van der Wall EE, Romijn JA, Bax JJ: Reversible diastolic dysfunction after long-term exogenous subclinical hyperthyroidism: a randomized, placebo-controlled study. J Clin Endocrinol Metab 2005;90:6041-6047.

48 Abdulrahman RM, Delgado V, Hoftijzer HC, Ng AC, Ewe SH, Marsan NA, Holman ER, Hovens GC, Corssmit EP, Romijn JA, Bax JJ, Smit JW: Both exogenous subclinical hyperthyroidism and short-term overt hypothyroidism affect myocardial strain in patients with differentiated thyroid carcinoma. Thyroid 2011;21:471-476.

49 Thavendiranathan P, Poulin F, Lim KD, Plana JC, Woo A, Marwick TH: Use of myocardial strain imaging by echocardiography for the early detection of cardiotoxicity in patients during and after cancer chemotherapy: a systematic review. J Am Coll Cardiol 2014; 63:2751-2768.
50 Shargorodsky M, Serov S, Gavish D, Leibovitz E, Harpaz D, Zimlichman R: Long-term thyrotropin-suppressive therapy with levothyroxine impairs small and large artery elasticity and increases left ventricular mass in patients with thyroid carcinoma. Thyroid 2006; 16:381-386

- 51 Horne MK 3rd, Singh KK, Rosenfeld KG, Wesley R, Skarulis MC, Merryman PK, Cullinane A, Costello R, Patterson A, Eggerman T, Bernstein DM, Pucino F, Csako G: Is thyroid hormone suppression therapy prothrombotic? J Clin Endocrinol Metab 2004; 89:4469-4473.

52 Abonowara A, Quraishi A, Sapp JL, Alqambar $\mathrm{MH}$, Saric A, O'Connell CM, Rajaraman MM, Hart RD, Imran SA: Prevalence of atrial fibrillation in patients taking TSH suppression therapy for management of thyroid cancer. Clin Invest Med 2012;35:E152-E156.

53 Wang L, Smith AW, Palmer FL, Tuttle RM M, Mahrous A, Nixon IJ, Patel SG, Ganly I, Fagin JA, Boucai L: TSH suppression increases the risk of osteoporosis without decreasing recurrence in ATA low and intermediate risk patients with differentiated thyroid carcinoma. Thyroid 2015;25:300-307.

54 Klein Hesselink EN, Klein Hesselink MS, de Bock GH, Gansevoort RT, Bakker SJ, Vredeveld EJ, van der Horst-Schrivers AN, van der Horst IC, Kamphuisen PW, Plukker JT, Links TP, Lefrandt JD: Long-term cardiovascular mortality in patients with differentiated thyroid carcinoma: an observational study. J Clin Oncol 2013;31:4046-4053.

55 Bassett JH, Williams GR: Critical role of the hypothalamic-pituitary-thyroid axis in bone. Bone 2008;43:418-426.

56 Bassett JH, Williams GR: The skeletal phenotypes of TR $\alpha$ and TR $\beta$ mutant mice. J Mol Endocrinol 2009;42:269-282.

57 O'Shea PJ, Harvey CB, Suzuki H, Kaneshige M, Kaneshige K, Cheng SY, Williams GR: A thyrotoxic skeletal phenotype of advanced bone formation in mice with resistance to thyroid hormone. Mol Endocrinol 2003; 17: 1410-1424.

58 O'Shea PJ, Bassett JH, Sriskantharajah S, Ying $\mathrm{H}$, Cheng SY, Williams GR: Contrasting skeletal phenotypes in mice with an identical mutation targeted to thyroid hormone receptor $\alpha 1$ or $\beta$. Mol Endocrinol 2005;19:3045-3059.

59 Abe E, Marians RC, Yu W, Wu XB, Ando T, Li Y, Iqbal J, Eldeiry L, Rajendren G, Blair HC, Davies TF, Zaidi M: TSH is a negative regulator of skeletal remodeling. Cell 2003;115:151162.

60 Verburg FA, Smit JW, Grelle I, Visser TJ, Peeters RP, Reiners C: Changes within the thyroid axis after long-term TSH-suppressive levothyroxine therapy. Clin Endocrinol 2012; 76:577-581.

-61 Sugitani I, Fujimoto Y: Effect of postoperative thyrotropin suppressive therapy on bone mineral density in patients with papillary thyroid carcinoma: a prospective controlled study. Surgery 2011;150:1250-1257.
Radioiodine Treatment and THST for DTC
Eur Thyroid J 2015;4:82-92 DOI: $10.1159 / 000432397$ 
-62 Kim MK, Yun KJ, Kim MH, Lim DJ, Kwon HS, Song KH, Kang MI, Baek KH: The effects of thyrotropin-suppressing therapy on bone metabolism in patients with well-differentiated thyroid carcinoma. Bone 2015;71:101105.

-63 Tournis S, Antoniou JD, Liakou CG, Christodoulou J, Papakitsou E, Galanos A, Makris K, Marketos H, Nikopoulou S, Tzavara I, Triantafyllopoulos IK, Dontas I, Papaioannou N, Lyritis GP, Alevizaki M: Volumetric bone mineral density and bone geometry assessed by peripheral quantitative computed tomography in women with differentiated thyroid cancer under TSH suppression. Clin Endocrinol 2015;82:197-204.

-64 Reverter JL, Colome E, Holgado S, Aguilera E, Soldevila B, Mateo L, Sanmarti A: Bone mineral density and bone fracture in male patients receiving long-term suppressive levothyroxine treatment for differentiated thyroid carcinoma. Endocrine 2010;37:467-472.

-65 Schneider R, Schneider M, Reiners C, Schneider P: Effects of levothyroxine on bone mineral density, muscle force, and bone turnover markers: a cohort study. J Clin Endocrinol Metab 2012;97:3926-3934.
66 Quan ML, Pasieka JL, Rorstad O: Bone mineral density in well-differentiated thyroid cancer patients treated with suppressive thyroxine: a systematic overview of the literature. J Surg Oncol 2002;79:62-69.

67 Franklyn JA, Betteridge J, Daykin J, Holder R Oates GD, Parle JV, Lilley J, Heath DA, Sheppard MC: Long-term thyroxine treatment and bone mineral density. Lancet 1992;340: 9-13.

68 Heijckmann AC, Huijberts MS, Geusens P, de Vries J, Menheere PP, Wolffenbuttel BH: Hip bone mineral density, bone turnover and risk of fracture in patients on long-term suppressive L-thyroxine therapy for differentiated thyroid carcinoma. Eur J Endocrinol 2005; 153:23-29.

69 Takamura Y, Miyauchi A, Yabuta T, Kihara M, Ito Y, Miya A: Attenuation of postmenopausal bone loss in patients with transient hypoparathyroidism after total thyroidectomy. World J Surg 2013;37:2860-2865

70 Kung AW, Yeung SS: Prevention of bone loss induced by thyroxine suppressive therapy in postmenopausal women: the effect of calcium and calcitonin. J Clin Endocrinol Metab 1996 81:1232-1236.
71 Rosen HN, Moses AC, Garber J, Ross DS, Lee SL, Ferguson L, Chen V, Lee K, Greenspan SL: Randomized trial of pamidronate in patients with thyroid cancer: bone density is not reduced by suppressive doses of thyroxine, but is increased by cyclic intravenous pamidronate. J Clin Endocrinol Metab 1998;83:23242330.

72 Mazzaferri EL, Young RL, Oertel JE, Kemmerer WT, Page CP: Papillary thyroid carcinoma: the impact of therapy in 576 patients. Medicine 1977;56:171-196.

73 Pujol P, Daures JP, Nsakala N, Baldet L, Bringer J, Jaffiol C: Degree of thyrotropin suppression as a prognostic determinant in differentiated thyroid cancer. J Clin Endocrinol Metab 1996;81:4318-4323.

74 Sugitani I, Fujimoto Y: Does postoperative thyrotropin suppression therapy truly decrease recurrence in papillary thyroid carcinoma? A randomized controlled trial. J Clin Endocrinol Metab 2010;95:4576-4583. 